\title{
Educação de qualidade na educação infantil: quanto custará aos municípios capixabas esse direito a partir do PNE 2014-2024?
}

\author{
Education of quality on early childhood education: how much will this right \\ cost to the municipalities of espirito santo from the PNE 2014-2014? \\ Educación de calidad en la educación infantil: ¿cuánto costará a los municipios \\ capixabas ese derecho a partir del PNE 2014-2024?

\section{EDSON MACIEL PEIXOTO VANIA CARVALHO DE ARAÚJO}

\begin{abstract}
Resumo: Este artigo demonstra como as políticas educacionais para a Educação Infantil, sobretudo as relacionadas à ampliação do acesso e à garantia da qualidade do ensino no âmbito do Plano Nacional de Educação 2014-2024, dependem de novas fontes de recursos financeiros e de uma nova matriz de financiamento e distribuição que contemplem a qualidade na perspectiva democrática. As análises, provenientes de pesquisa bibliográfica, documental e de simulação do Custo Aluno-Qualidade (CAQ) para a Educação Infantil capixaba, revelam a emergência da implementação do Custo Aluno-Qualidade Inicial (CAQi) como referência para a garantia de padrões mínimos de qualidade nessa etapa da Educação Básica, bem como o necessário aporte de recursos financeiros da União que possibilitem a implementação por todos e em todos os lugares dessa nova matriz de financiamento.
\end{abstract}

Palavras-chave: educação de qualidade na Educação Infantil; custo-alunoqualidade inicial; direito à educação e padrões mínimos de qualidade.

\begin{abstract}
This article demonstrates how educational policies for early childhood education, especially those related to the expansion of access and quality assurance in education under the National Education Plan 2014-2024; depend on new sources of financial resources and a new matrix of financing and distribution that considers quality in a democratic perspective. The analysis bases on a bibliographic, documentary and simulation study of the Quality Student Cost (CAQ) for the early childhood education of the state of Espírito Santo. It reveals the emergence of the implementation of the Initial Quality Student Cost (CAQi) as reference for the guarantee of minimum standards of quality in children's education, as well as the necessary financial resources from the Union to enable the implementation by all and everywhere of the new funding matrix.
\end{abstract}

Keywords: Education of quality on childhood education; initial quality student cost; right to education; minimum quality standards. 
Resumen: Este artículo demuestra cómo las políticas educativas para la educación infantil, sobre todo aquellas relacionadas a la ampliación de acceso y a la garantía de la calidad en la enseñanza en el ámbito del Plan Nacional de Educación 2014-2024, dependen de nuevos fuentes de recursos financieros y de una nueva matriz de financiamiento y distribución que contemple la calidad en la perspectiva democrática. Los análisis, provenientes de investigación bibliográfica, documental y de simulación del Costeo Alumno-Calidad (CAQ) para la educación infantil capixaba, revelan la emergencia de la implementación del Costeo Alumno-Calidad Inicial (CAQi) como referencia para la garantía de patrones mínimos de calidad en la educación infantil, así como el necesario aporte de recursos financieros de la Unión que posibiliten la implementación por todos y en todos los lugares de esa nueva matriz de financiamiento.

Palabras clave: Educación de calidad en la educación infantil; costeo-alumnocalidad inicial; derecho a la educación y patrones mínimos de calidad.

\section{INTRODUÇÃO}

Este artigo analisa as questões referentes ao tema do direito à educação de qualidade na Educação Infantil a partir da vertente do financiamento, ou seja, dimensiona o quantitativo de recursos financeiros necessários para se garantirem os padrões mínimos de qualidade no ensino prescritos como princípio na Constituição de 1988. Destacou-se, nesse sentido, o trabalho realizado pelo Conselho Nacional de Educação, em parceria com a Campanha Nacional pelo Direito à Educação, cujo objetivo foi o de regulamentar esse princípio constitucional. A proposta em tela contemplou, entre outros aspectos, os insumos necessários e os parâmetros de qualidade que devem ser considerados para a promoção de uma educação para todos, com iguais oportunidades e qualidade sob o ponto de vista democrático, dissociados da ideia do direito ao acesso e à qualidade para poucos, ou seja, como privilégio e não como direito. Surge desses insumos e parâmetros, devidamente contabilizados, os aportes financeiros necessários, a matriz referencial do CustoAluno- Qualidade (CAQ).

O artigo apresenta, de modo mais específico, como as políticas educacionais para a Educação Infantil, prescritas nas normas constitucionais e infraconstitucionais, sobretudo aquelas afetas à ampliação do acesso e à garantia da qualidade no ensino no âmbito do Plano Nacional de Educação (PNE) 20142024, dependem de novas fontes de recursos financeiros e de uma nova matriz de financiamento e distribuição que contemplem a qualidade na perspectiva democrática, ou seja, a mesma qualidade para todos e em todos os lugares. Evidencia, ainda, a incapacidade da Política de Fundos para garantir padrões mínimos de qualidade, uma vez que se estrutura pela via da distribuição de recursos arrecadados e não pela qualidade dos insumos necessários ao processo de ensino-aprendizagem. 
Para essa empreitada, realizou-se uma pesquisa bibliográfica e documental, especialmente dos dados primários disponibilizados pelo Instituto Brasileiro de Geografia e Estatística (IBGE) e pelo Instituto Nacional de Estudos e Pesquisas Educacionais Anísio Teixeira (Inep), bem como um exercício de simulação do Custo Aluno-Qualidade Inicial (CAQi) para a Educação Infantil capixaba, a partir de um software denominado simCAQ. ${ }^{1}$

Nesse sentido, o artigo foi organizado em duas partes. Na primeira, discutem-se a relação entre o dever de educar e o direito à educação das crianças nas creches e pré-escolas, a partir das legislações que contemplam possibilidades e desafios à efetivação do dever e do direito das crianças à educação. Na segunda, apresentam-se, a partir da aplicação da matriz de financiamento do CAQi e do simCAQ, os insumos e parâmetros utilizados na simulação, bem como se analisam os impactos da Meta 1 do PNE sobre o financiamento de cada uma das etapas da Educação Infantil no Estado do Espírito Santo.

\section{O DEVER DE EDUCAR E O DIREITO À EDUCAÇÃO}

O dever do Estado com a educação, mediante a oferta da Educação Infantil, tem seu referencial no art. 208 da Constituição Federal, alterado pela EC $n^{\circ}$ 53/2006, que garante a oferta da "Educação Infantil, em creche e pré-escola às crianças até 5 (cinco) anos de idade" (BRASIL, 1988, art. 208, IV). A Lei de Diretrizes e Bases da Educação Nacional (LDB/1996) especificou a Educação Infantil como primeira etapa da Educação Básica, sob a responsabilidade dos municípios (BRASIL, 1996).

Essas normatizações possibilitaram à Educação Infantil acessar alguns programas e políticas, por exemplo: a) sua inclusão no rol das etapas e modalidades partícipes do Fundo de Manutenção e Desenvolvimento da Educação Básica e de Valorização dos Profissionais da Educação (Fundeb), garantindo uma nova fonte de recursos aos municípios (BRASIL, 2007); b) a inclusão da garantia de acesso às crianças, ao completarem quatro anos de idade, a vagas em instituições públicas de Educação Infantil mais próximas de sua residência (BRASIL, 2008a). Outra norma que influenciou diretamente a Educação Infantil foi a Lei no ${ }^{\circ} 11.738 / 2008$, que instituiu o piso profissional nacional para os profissionais do magistério público da Educação Básica (BRASIL, 2008b), criado pela EC no 53/2006.

Por sua vez, a EC n ${ }^{\circ}$ 59/2009 reforçou o dever do Estado, incorporando a educação das crianças de quatro e cinco anos à faixa de obrigatoriedade e gratuidade da Educação Básica e, por conseguinte, como direito público subjetivo,

1 simCAQ: Software simulador do custo-aluno-qualidade, versão 2.0, cedido por um dos responsáveis pelo projeto, Prof. Thiago Alves - Universidade Federal do Paraná (UFPR). 
podendo seu atendimento pelos Poderes Públicos ser exigido pelas famílias. A implementação progressiva dessa extensão de obrigatoriedade deve atingir a universalização da oferta de matrículas na etapa pré-escolar da Educação Infantil até o ano de 2016, nos termos do art. $6^{\circ}$ da referida EC (BRASIL, 2009).

Além do dever do Estado, foi sancionada a Lei no 12.796/2013, que estabelece, por um lado, que "É dever dos pais ou responsáveis efetuar a matrícula das crianças na educação básica a partir dos 4 (quatro) anos de idade" (BRASIL, 2013b, art. $6^{\circ}$ ) e, por outro, o "Controle de frequência pela instituição de educação pré-escolar, exigida a frequência mínima de $60 \%$ (sessenta por cento) do total de horas" (Idem, art. 31, IV).

Em análise sobre as consequências da vigência dessa lei para a família ou responsáveis e para os gestores municipais, Peixoto, Schuchter e Araújo (2015) argumentam que a sua sanção

Acaba por gerar responsabilidade imediata tanto para a família ou responsáveis, quanto para os municípios. Para a família, a inobservância da matrícula pode implicar abandono intelectual, que figura entre os crimes contra a assistência familiar, previsto no art. 246 do Código Penal brasileiro ${ }^{2}$ [...]. Em relação aos gestores municipais, eles tornam-se obrigados a deferir os pedidos de matrículas das crianças de quatro e cinco anos, imediatamente à demanda apresentada, sob pena de incorrer em crime de responsabilidade, conforme estabelece a Lei de Diretrizes e Bases da Educação (p. 132-133).

Esse dever do Estado de universalização das matrículas na idade préescolar é repetido na Meta 1 da Lei no 13.005/2014, que aprova o PNE-20142024. Nessa mesma meta, anuncia-se a ampliação da oferta de Educação Infantil em creches, de forma a atender, no mínimo, a 50\% das crianças de até três anos de idade até o final da vigência do PNE, ou seja, 2024. Portanto, uma vez atingida essa Meta, estarão matriculadas na Educação Infantil, em 2016, na pré-escola, 100\% das crianças de quatro e cinco anos, ou seja, algo em torno de 6.004 .000 crianças. Por sua vez, em 2024, as creches contarão com $50 \%$ das crianças com idade entre zero e três anos, ou seja, 5.262 .674 crianças, segundo estimativa populacional realizada pelo Instituto Brasileiro de Geografia e Estatísticas (IBGE, 2016).

Mas, qual o diagnóstico a respeito das matrículas na Educação Infantil? Quantas crianças estão matriculadas e que desafios se apresentam aos municípios ${ }^{3}$ para atendimento à garantia do direito das crianças à educação?

\footnotetext{
2 Cf. (BRASIL, 1940).

3 Importante ressaltar que, para fins deste artigo, optou-se por apresentar e analisar os dados do Estado do Espírito Santo.
} 
No caso da universalização do acesso à pré-escola, prescrita na Meta 1 do PNE para efetivação no ano letivo de 2016, o desafio dos municípios brasileiros é matricular cerca de 546.000 crianças, ou seja, $9,91 \%$ da população residente que se encontrava, no ano de 2014, na faixa etária de quatro e cinco anos ${ }^{4}$ (Gráfico 1).

Em relação ao acesso à creche, tendo como referência a Meta 1 do PNE, que prevê o atendimento a 50\% das crianças de zero a três anos para 2024, comparando-se com as matrículas do ano de 2014, o desafio dos municípios deve ser a expansão da matrícula em, aproximadamente, 2.371 .000 crianças $(81,98 \%$ de acréscimo), ou seja, praticamente dobrar a oferta de 2014, conforme demostrado no Gráfico 2. Esse Quantitativo implicará o atendimento a 50\% das crianças de zero a três anos de idade, percentual que, em 2014, representava 27,48\%.

\section{Gráfico 1 - Relação entre a população de quatro e cinco anos de idade e as matrículas na pré-escola-Brasil}

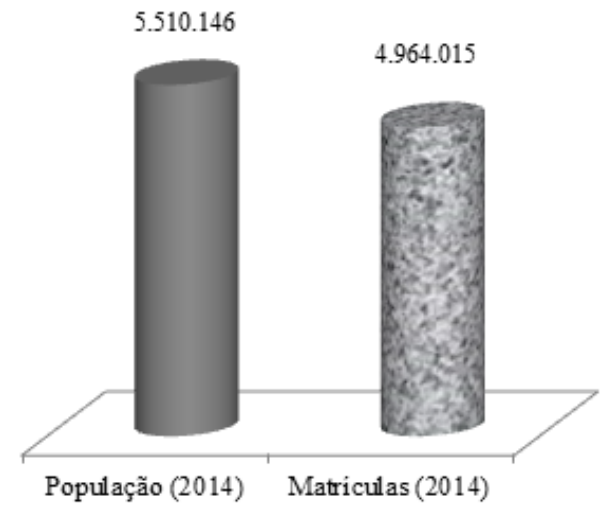

Fonte: elaboração dos autores a partir de dados do IBGE (2014) e do Inep (2014).

4 Pesquisa Nacional de Amostra Domiciliar (PNAD), realizada no ano de 2014. (IBGE, 2014). Os dados das matrículas de 2014 foram apurados a partir do Censo Escolar da Educação Básica (Inep, 2014). 


\section{Gráfico 2 - Relação entre a população prevista de zero a três anos de idade e as matrículas na creche - Brasil}

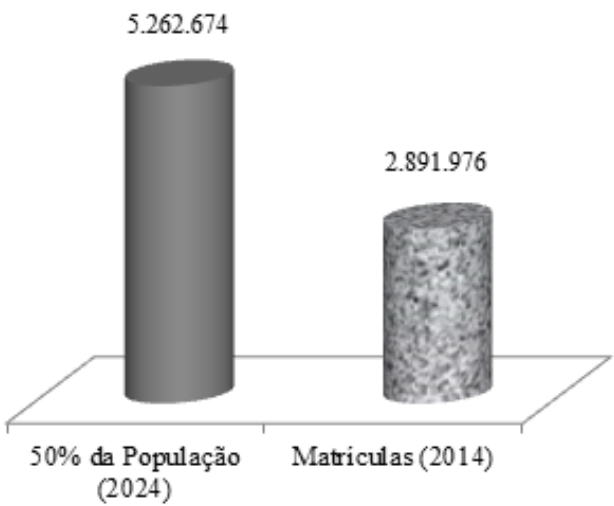

Fonte: elaboração dos autores a partir de dados do IBGE (2014) e do Inep (2014).

$\mathrm{Na}$ comparação dos desafios que os municípios enfrentarão para a expansão da educação infantil, os dados coletados apontam que as vagas nas préescolas capixabas necessitarão ser acrescidas, em números percentuais maiores do que a média nacional. Para uma população de 112.240 crianças na faixa etária dos quatro e cinco anos, os municípios matricularam, no ano de 2014, um total de $97.914(87,24 \%)$ crianças. Esse retrato implica a necessidade de expansão de 14.236 vagas, ou seja, 12,76\% a mais do que a oferta do ano de 2014 (Gráfico 3), percentual que representa a necessidade de um grande empenho dos municípios, principalmente se tomados em comparação a expansão dos últimos quatro anos que foi da ordem de 2,1\%, conforme dados do Observatório do PNE. ${ }^{5}$

No entanto, ao levantarmos os dados da creche, verificou-se que os municípios capixabas se encontram em melhor situação do que a totalidade dos municípios brasileiros. Enquanto estes necessitarão quase que dobrar (81,98\%) o quantitativo de matrículas ofertadas no ano de 2014, aqueles precisarão ampliar em 50,63\%, até o ano de 2024 o quantitativo de matrículas (Gráfico 4).

5 Cf. Observatório do PNE (2016). 
Gráfico 3 - Relação entre a população de quatro e cinco anos de idade e as matrículas na pré-escola - Espírito Santo

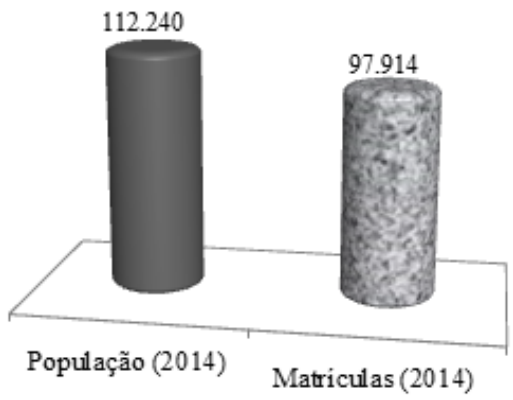

Fonte: elaboração dos autores a partir de dados do IBGE (2014) e do Inep (2014).

\section{Gráfico 4 - Relação entre a população prevista de zero a três anos de idade e as matrículas na creche - Espírito Santo}

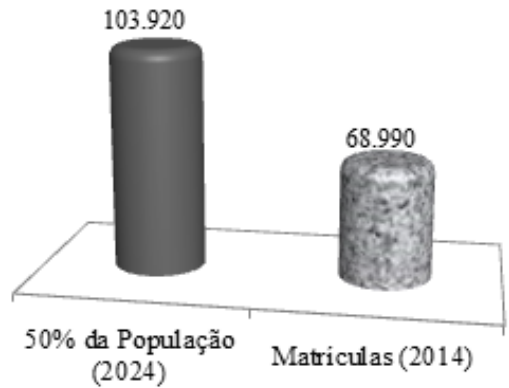

Fonte: elaboração dos autores a partir de dados do IBGE (2014) e do Inep (2014).

Esse empenho dos municípios implica igualar os indicadores entre o direito das crianças à Educação Infantil, tanto na creche, quanto na pré-escola e o dever do Estado em educar. Como nos diz Oliveira (2007), esse dispositivo infraconstitucional, "Se transformado em realidade, avança em termos da efetivação da igualdade de todos perante a lei, pois um dos mecanismos mais conhecidos da exclusão já não se produz no caminho até a escola (falta de vagas, por exemplo)" (p. 23).

Entretanto, a diferença cronológica de oito anos para o atingimento dos dois quesitos, universalização do acesso à pré-escola no ano de 2016 e ampliação da oferta nas creches até o ano de 2024, pode implicar "Desobrigação 
dos entes federados, em especial os municípios, com a expansão e melhoria da oferta da educação de 0 a 3 anos" (DOURADO, 2010, p. 691). Corroboram esse apontamento os dados do Inep (2014), os quais apresentam que foram os municípios que mais se responsabilizaram pelas matrículas públicas de Educação Infantil (98,95\%). No caso dos municípios capixabas, esse percentual foi de $99,90 \%$.

Esse quadro aponta para a necessidade de um envolvimento dos diversos e diferentes atores sociais, de forma a mobilizar recursos para o acompanhamento das ações que as secretarias municipais de Educação irão realizar ao longo desse processo. A "participação ativa", ou melhor, a "Capacidade de mobilização para a ação, conhecimento aprofundado de direitos, deveres e possibilidades de participação, atenção e vigilância em relação a todos os aspectos considerados pertinentes" (LIMA, 2003, p. 77), parece-nos constituir-se como importante estratégia de envolvimento e mobilização da sociedade para garantir a expansão da oferta de Educação Infantil descolada da ideia de privilegiar uma etapa (préescola) em detrimento da outra (creche).

Diante do contexto até aqui apresentado do dever constitucional do Estado na oferta gratuita da Educação Infantil pré-escolar a todas as crianças e da norma infraconstitucional que prevê a expansão da matrícula nas creches, bem como do alerta da possibilidade, em curtíssimo prazo, de redução de vagas para as crianças de zero a três anos de idade para efetivação da ampliação das matrículas obrigatórias de quatro e cinco anos, questiona-se sobre a existência de mecanismos que garantam as medidas de expansão do direito à Educação Infantil em todas as suas etapas.

A esse respeito Oliveira (2007) afirma que "A garantia constitucional destes serviços, ainda que formulada de maneira incompleta, possibilita ampliar a luta pela sua efetivação para o âmbito do Sistema de Justiça” (p. 27), o que implicou, em grande medida, judicialização da educação. Nesse sentido, ainda que essa questão da expansão do acesso exija esforço técnico e financeiro, principalmente do ente federado municipal, as demandas por vagas possuem as bases jurídicas para seu reclame e equalização da questão do acesso.

Em diferente perspectiva, encontra-se o direito à educação, tomado a partir da dimensão qualidade, explicitado na constituição vigente. A não explicitação do que venha a constituir-se como parâmetros mínimos de qualidade acaba por gerar dificuldades objetivas para se reclamar tal direito constitucional.

Mas que parâmetros de qualidade poderão ser embutidos nessa adjetivação do direito à educação, de forma que seja possível, em caso de não atendimento pelo Poder Executivo, garanti-los por meio das instâncias do Poder Judiciário, da mesma forma como é possível com as demandas por vagas na Educação Infantil? 


\section{O DIREITO À EDUCAÇÃO INFANTIL DE QUALIDADE: QUAL O INVESTIMENTO NECESSÁRIO PARA GARANTIR ESSE DIREITO?}

O direito à educação, para além da sua referência ao dever de educar cuja dimensão se relaciona com o direito positivado em normas jurídicas, encontra vinculação à qualidade educacional socialmente referenciada. Em estudo realizado pela Campanha Nacional pelo Direito à Educação, o conceito de qualidade em educação foi entendido como "Historicamente construído e em disputa" (CARREIRA; PINTO, 2007), ou seja, depende da época, do lugar, dos sujeitos e dos projetos de sociedade em disputa. A Campanha formulou o entendimento da qualidade em educação como um processo que:

\footnotetext{
Gere sujeitos de direitos, de aprendizagem e de conhecimento, sujeitos de vida plena;

é comprometido com a inclusão cultural e social, uma melhor qualidade de vida no cotidiano, o respeito à diversidade, o avanço da sustentabilidade ambiental e da democracia e a consolidação do Estado de Direito; [...] exige investimentos financeiros em longo prazo e o reconhecimento das diversidades culturais, sociais e políticas; [...] reconhece e enfrenta as desigualdades sociais em educação, devidamente contextualizado no conjunto das políticas sociais e econômicas do País;

[...] referencia[-se] nas necessidades, nos contextos e nos desafios do desenvolvimento de uma região, de um país, de uma localidade; [...] está indissociado da quantidade, da garantia do acesso ao direito à educação; [...] se aprimora por meio da participação social e política, garantida por meio de uma institucionalidade e de processos participativos e democráticos que independem da vontade política do gestor ou da gestora em exercício. (p. 24).
}

Esses referenciais de qualidade vão de encontro a outros que se vinculam à qualidade em educação por meio: a) de indicadores extraídos das avaliações externas de larga escala; b) da exclusiva relação com a expansão do número de crianças matriculadas nas instituições educativas; c) dos casos isolados de assunção da qualidade, portanto, privilégio para poucos.

A adoção daqueles referenciais como componentes do conceito de qualidade em educação provocou a necessidade de se repensar a matriz de distribuição de recursos entre os entes federados. O modelo vigente de financiamento da Educação Básica (Fundeb), no qual os fundos estaduais e distrital organizam os respectivos recursos financeiros subvinculados à educação e os devolve proporcionalmente ao número de matrículas ponderadas de todas as etapas da Educação Básica, parece não ter o poder de viabilizar o direito de todos à educação baseado em referenciais de qualidade. 
Trazer à matriz de financiamento os referenciais de qualidade em educação formulados pela Campanha Nacional pelo Direito à Educação implica colocar em xeque a própria "matemática" da distribuição dos recursos aplicada atualmente pelo Fundeb. Nessa "matemática”, o valor por aluno é obtido pela divisão do montante do Fundo pelo número de matrículas ponderadas, levando-se em consideração apenas o quantitativo de recursos disponíveis e não os referenciais de qualidade. A manutenção dessa "matemática" da distribuição resultará em queda do valor do Fundeb por matrícula em função da expansão nas matrículas preconizadas pela EC no 59/2009 e pelas metas do PNE. Essa evidência já foi apontada por Pinto e Alves (2011) ao demonstrarem que, no caso do Estado do Espírito Santo, essa queda gira em torno de 8,5\% no valor/aluno do Fundeb. Indicam, ainda, que, para não haver essa redução, seriam necessários recursos na ordem de 167 milhões de reais, em valores de 2010.

Essa combinação de dados confirma a necessidade, já apontada desde os anos iniciais do século XXI, pela Campanha Nacional pelo Direito à Educação, de formulação e implementação de uma nova política de financiamento para a educação, que pudesse atender, ao mesmo tempo, sem priorizações, à expansão das matrículas e à garantia do padrão mínimo de qualidade do ensino.

Surge daí a proposta do CAQ, com o intuito de promover a mudança do referencial da vigente Política de Fundos. Assim, a pergunta não seria mais o quanto de recursos os entes federados possuem para aplicar na educação básica, e sim:

Qual é o investimento necessário por criança (no caso das creches) ou por estudante (no caso das escolas) para que o Brasil cumpra a legislação educacional e garanta condições para a ampliação do número de vagas e para a melhoria da qualidade de educação? Quanto custa fazer valer esse direito? (CAMPANHA NACIONAL PELO DIREITO À EDUCAÇÃO, 2011, p. 9).

Para viabilizar a resposta a essas questões e, baseando-se nos referenciais do conceito de qualidade assumido pela Campanha, foram definidas quatro categorias de insumos, relacionadas ao processo de ensino-aprendizagem: estrutura e funcionamento, trabalhadores e trabalhadoras em educação, gestão democrática e acesso e permanência na escola.

No caso da Educação Infantil, quais seriam esses insumos? Quais são os parâmetros de qualidade a serem adotados? Quanto custa para que o direito à Educação Infantil seja efetivado a partir de padrões de qualidade?

Para tentar responder a essas questões, serão tomados como base os parâmetros do Custo Aluno-Qualidade Inicial (CAQi) para a Educação Infantil no Estado do Espírito Santo. O CAQi, na Educação Infantil é um mecanismo que 
traduz em valores o quanto é necessário investir por criança/ano para garantir um padrão mínimo de qualidade do ensino.

Nesse sentido, por meio das possibilidades do simulador de custo-alunoqualidade (simCAQ), foram definidos os parâmetros a serem utilizados para fins do cálculo dos valores de investimento do CAQi por criança/ano na Educação Infantil do Estado do Espírito Santo.

CAQi Educação Infantil urbana (creche e pré-escola)

Parâmetros utilizados na simulação ${ }^{6}$

- Metas de atendimento

o Creche: $50 \%$ da população residente de 0 a 3 anos de idade até o ano de 2024.

o Pré-escola: $100 \%$ da população residente de 4 e 5 anos de idade até o ano de 2016.

- Número de dias letivos por semana: 5 dias.

- Carga horária diária: 5 horas (parcial) e 10 horas (integral).

- Meta de implantação de escola em tempo integral: 50\% das turmas até o ano de 2024.

- Jornada de trabalho semanal dos docentes: 40 horas, sendo 1/3 para atividades de planejamento.

- Número máximo de crianças por turma:

o Creche: 11 crianças

o Pré-escola: 20 crianças

- Percentual de professores que possuem formação em nível médio

o Creche: $85 \%$

o Pré-escola: 50\%

- Percentual de professores que possuem formação em nível superior

o Creche: $15 \%$

o Pré-escola: $50 \%$

- Carreira dos docentes com formação de nível médio, distribuição dos professores na carreira e salário inicial em cada nível, de acordo com o Departamento Intersindical de Estatística e Estudos Socioeconômicos DIEESE:

o Professor N-I: 33,3\% - Salário inicial de R $\$ 2.388,88$

o Professor N-II: 33,3\% - Salário inicial de R \$2.977,87

o Professor N-III: 33,4\%- Salário inicial de R \$3.665,08

6 Nos limites das possibilidades de customização do simCAQ pelo usuário, foram utilizados os parâmetros de qualidade aprovados pelo Conselho Nacional de Educação (CNE), por meio do Parecer CNE/ CEB n ${ }^{\circ} 8 / 2010$ (CNE, 2010). 
- Carreira dos docentes com formação de nível superior, distribuição dos professores na carreira e salário inicial em cada nível, de acordo com o DIEESE :

o Professor N-I: 33,3\% - Salário inicial de R \$ 4.212,01

o Professor N-II: 33,3\% - Salário inicial de R \$ 5.475,62

o Professor N-III: 33,4\% - Salário inicial de R\$ 6.738,96

- Composição quadro de profissionais não docentes, distribuição nos níveis da carreira, critérios de alocação (Tabela 1)

Tabela 1 - Profissionais não docentes por níveis de carreira e critérios de alocação

\begin{tabular}{|c|c|c|c|}
\hline \multirow{2}{*}{ Profissional /Nível de carreira } & Percentual por nível da & \multicolumn{2}{|c|}{ Critério de alocação nas creches } \\
\cline { 3 - 4 } & carreira & $\begin{array}{c}\text { No de crianças } \\
\text { por profissional }\end{array}$ & $\begin{array}{c}\text { Mínimo por } \\
\text { creche }\end{array}$ \\
\hline Diretor(a) N-I & $33,3 \%$ & 1000 & 1 \\
\hline Diretor(a) N-II & $33,3 \%$ & 1000 & 1 \\
\hline Diretor(a) N-III & $33,4 \%$ & 1000 & 1 \\
\hline Auxiliar de Secretaria N-I & $33,3 \%$ & 250 & 1 \\
\hline Auxiliar de Secretaria N-II & $33,3 \%$ & 250 & 1 \\
\hline Auxiliar de Secretaria N-III & $33,4 \%$ & 250 & 1 \\
\hline Coordenador(a) pedagógico(a) N-I & $33,3 \%$ & 250 & 1 \\
\hline Coordenador(a) pedagógico(a) N-II & $33,3 \%$ & 250 & 1 \\
\hline Coordenador(a) pedagógico(a) N-III & $33,4 \%$ & 250 & 1 \\
\hline Bibliotecário(a) N-I & $33,3 \%$ & 450 & 1 \\
\hline Bibliotecário(a) N-II & $33,3 \%$ & 450 & 1 \\
\hline Bibliotecário(a) N-III & $33,4 \%$ & 450 & 1 \\
\hline Auxiliar de manutenção e infraestrutura - NII & $33,3 \%$ & 100 & 2 \\
\hline Auxiliar de manutenção e infraestrutura - NIII & $33,4 \%$ & 100 & 2 \\
\hline
\end{tabular}

Fonte: Criação dos autores a partir do relatório gerado pelo simCAQ.

- Encargos sociais: 20\%

- Número de refeições servidas às crianças por dia: tempo parcial - uma refeição; tempo integral - duas refeições

- Infraestrutura das creches

o Sala de leitura / Biblioteca

o Sala de direção/equipe

o Sala de professores

o Copa/cozinha

o Parque infantil 
o Banheiros

o Berçário

o Dependência adaptada para pessoas com deficiência

o Banheiros adaptados para pessoas com deficiência

o Adequação do prédio para acesso à internet

o Adequação do prédio para fornecimento de energia

o Adequação do prédio para abastecimento de água

o Adequação do prédio para coleta de esgoto

o Adequação do prédio para instalação de banda larga

- Funcionamento e manutenção das escolas

o Água/luz/telefone

o Acesso à internet

o Material de limpeza

o Material didático

o Projetos de ação pedagógica

o Material de escritório

o Conservação predial

o Manutenção e reposição de equipamentos

- Administração e supervisão da rede

- Formação de profissionais

- Índices de preços utilizados

o Índice Nacional de Preços ao Consumidor (INPC/IBGE)

o Índice Nacional da Construção Civil (INCC/FGV)

o Índice de Custo de Vida (ICV/DIEESE)

Inseridos esses parâmetros no simCAQ, foram obtidos os valores do Custo-Aluno-Ano e os recursos necessários para a garantia do direito à educação a partir de padrões mínimos de qualidade (Tabela 2):

\section{Tabela 2 - Simulação do Custo-Aluno-Ano da Educação Infantil - Espírito Santo}

\begin{tabular}{|c|c|c|c|c|}
\hline Ano de referência & Etapa & CAQi criança-ano $(\mathrm{R} \$)$ & Total de recursos necessários ( $\mathrm{R} \$$ ) & Investimento com pessoal (\%) \\
\hline 2014 & Creche & $\mathrm{R} \$ 8.739,00$ & $\mathrm{R} \$ 482.434 .798,00$ & $75,75 \%$ \\
\hline & Pré-escola & $\mathrm{R} \$ 7.023,00$ & $\mathrm{R} \$ 286.253 .686,00$ & $71,98 \%$ \\
\hline 2015 & Creche & $\mathrm{R} \$ 8.947,00$ & $\mathrm{R} \$ 514.949 .780,00$ & $76,13 \%$ \\
\hline & Pré-escola & $\mathrm{R} \$ 7.152,00$ & $\mathrm{R} \$ 577.484 .273,00$ & $72,34 \%$ \\
\hline 2016 & Creche & $\mathrm{R} \$ 9.185,00$ & $\mathrm{R} \$ 553.624 .698,00$ & $76,53 \%$ \\
\hline & Pré-escola & $\mathrm{R} \$ 7.310,00$ & $\mathrm{R} \$ 584.793 .224,00$ & $72,77 \%$ \\
\hline
\end{tabular}

Fonte: Elaboração dos autores a partir do relatório gerado pelo simCAQ. 
Em análise comparativa com o Fundeb dos respectivos anos de referência, verificou-se a deficitária distribuição de recursos pela Política dos Fundos em relação ao CAQi. No caso das creches, seria necessário uma vez e meia a mais de recursos para investimentos por criança/ano. Na pré-escola, é um pouco menor a relação, mas nunca menos do que o dobro de recursos (Gráfico 5).

\section{Gráfico 5 - Comparação entre o investimento por criança-ano pelo Fundeb e pelo CAQi}

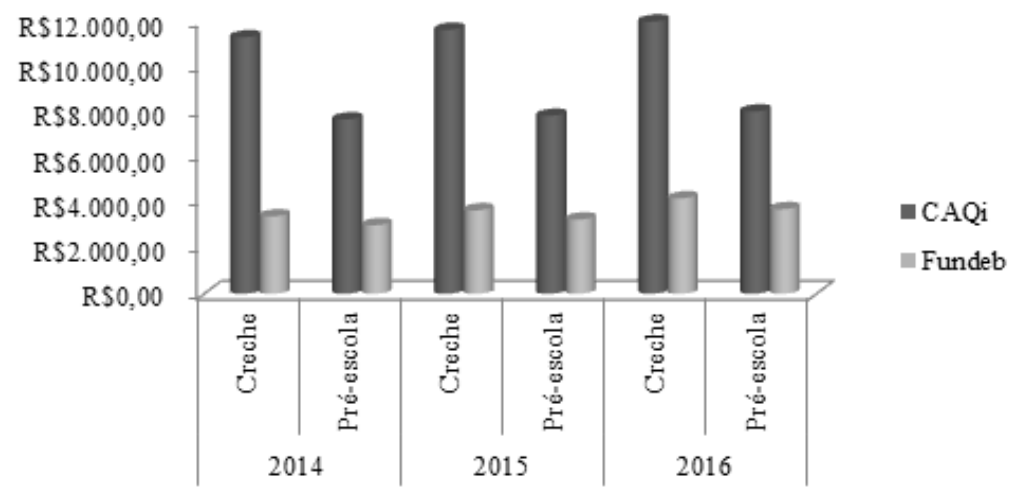

Fonte: Elaboração dos autores a partir do relatório gerado pelo simCAQ e das tabelas dos valores anuais do Fundeb (BRASIL, 2013a, 2014a, 2015a).

Esses dados do Gráfico 5 demonstram a emergência e a urgência de mobilização em torno da efetiva adoção do CAQi como parâmetro para a distribuição de recursos aos entes federados, para que o PNE 2014-2024 seja cumprido em suas dimensões de expansão da quantidade e de garantia de padrões mínimos de qualidade na educação em geral e na Educação Infantil especificamente.

Vale ressaltar a necessidade de ampliação dos recursos nominais, mediante a complementação da União, uma vez que os demais entes federados, em sua maioria, não conseguirão, neste momento, garantir o montante de recursos necessários para implementação do CAQi. Esse complemento está previsto na estratégia 20.10 do PNE 2014-2024: “Caberá à União, na forma da lei, a complementação de recursos financeiros a todos os Estados, ao Distrito Federal e aos Municípios que não conseguirem atingir o valor do CAQi e, posteriormente, do CAQ" (BRASIL, 2014b). No caso da Educação Infantil no contexto do Estado do Espírito Santo, o montante de recursos a ser complementado pela União, somente para este ano de 2016 , seria de aproximadamente de $\mathrm{R} \$ 800$ milhões de reais. 
Da mesma forma o aporte de recursos complementares se faz importante para a implementação de políticas de valorização dos profissionais da educação, docentes e não docentes. A adoção dos parâmetros do CAQi na Educação Infantil, relacionados com os trabalhadores e trabalhadoras da educação, pode ser inviabilizada pelo limite da Lei de Responsabilidade Fiscal, que estabelece o teto de 54\% da Receita Corrente Líquida (RCL) para gastos com pessoal do Poder Executivo. O acréscimo de RCL implica aumento do capital disponível para gasto com docentes e não docentes.

\section{CONSIDERAÇÕES FINAIS}

Parece não haver dúvidas quanto à necessidade de se mudar a matriz de referência do Custo-Aluno-Anual, abandonando-se a fórmula do Fundeb pelo CAQi. Por conseguinte, a maneira pela qual se realiza a distribuição de recursos entre os entes federados também precisa ser modificada. A prática da União, de retirar dos municípios com alto volume de arrecadação as verbas da educação para suprir "colaborativamente" os municípios que pouco arrecadam, dentro do mesmo Estado, parece ter seus dias contados, na hipótese da efetiva implementação do CAQi.

O dever de educar e o direito à educação das crianças em uma perspectiva de qualidade implica, além das questões afetas à mudança na matriz de referência do Custo-Aluno-Anual, a necessidade de mais e novos recursos para a educação. Se mantidos os mesmos valores nominais, a expansão das matrículas previstas no PNE 2014-2024 representará mais acesso e menos recursos/aluno/ano.

Em relação aos novos recursos anunciados para a educação, esses parecem dissolver-se a cada instante no Brasil. Um primeiro ponto se relaciona com os recursos do pré-sal, degenerados pela queda dos valores das ações da Petrobrás, que reduzem o capital de investimento em novas tecnologias e práticas de retirada do petróleo, pela vertiginosa queda do preço do barril de petróleo e pela proposta de alteração da lei do pré-sal. Assim, esse recurso financeiro, não obstante representar o que outrora anunciavam - o novo dinheiro para a educação - dificilmente será no montante que se proclamava.

Outro ponto de destaque é a objetivada criação da Desvinculação das Receitas dos Estados e Distrito Federal e da Desvinculação das Receitas dos Municípios. Essa Proposta de Emenda à Constituição (PEC), no 143/2015, originada no Senado Federal, se aprovada, representará que os 25\% de gastos obrigatórios de Estados, Distrito Federal e Municípios com a educação não mais incidirão sobre os $100 \%$ dos valores arrecadados, mas sim sobre os $75 \%$, 
representando uma perda de 25\% na destinação de verbas de Estados, Distrito Federal e Municípios para a educação (BRASIL, 2015b)

Sem dúvida, esse quadro põe em risco a implementação do CAQi, mas, principalmente, coloca em xeque o PNE 2014-2024 e sua perspectiva de efetivação da garantia do acesso e dos padrões mínimos de qualidade no ensino a todos e todas em todos os lugares.

\section{REFERÊNCIAS}

BRASIL. Portaria Interministerial $\mathrm{n}^{\circ}$ 11, 30 dez. 2015. Parâmetros anuais do Fundeb - 2016. Diário Oficial [da] República Federativa do Brasil, Brasília, 31 dez. 2015a. Seção 1.

Proposta de emenda à Constituição no 143, de 4 de novembro de 2015. Diário do Senado Federal. Brasília, 5 nov. 2015b, p. 112.

Portaria Interministerial $\mathrm{n}^{\circ}$ 17, 29 dez. 2014. Parâmetros anuais do Fundeb - 2015. Diário Oficial [da] República Federativa do Brasil, Brasília, 30 dez. 2014a. Seção 1.

Lei $\mathrm{n}^{\circ}$ 13.005, de 25 de junho de 2014. Aprova o Plano Nacional de Educação (PNE) e dá outras providências. Brasília: Diário Oficial [da] República Federativa do Brasil, Brasilia, 26 jun. 2014b. Seção 1, p. 1, Ed. Extra.

Portaria Interministerial $\mathrm{n}^{\circ}$ 19, 27 dez. 2013. Parâmetros anuais do Fundeb - 2014. Diário Oficial [da] República Federativa do Brasil, Brasília, 30 dez. 2013a. Seção 1.

Lei no 12.796, de 04 de abril de 2013. Altera a Lei no 9.394, de 20 de dezembro de 1996, que estabelece as diretrizes e bases da educação nacional, para dispor sobre a formação dos profissionais da educação e dar outras providências. Diário Oficial [da] República Federativa do Brasil, Brasília, 5 abr. 2013b. Seção 1, p. 1.

Constituição (1988). Emenda constitucional no 59, de 11 de novembro de 2009. Diário Oficial [da] República Federativa do Brasil, Brasília, 12 nov. 2009. Seção 1, p. 8 
Lei $\mathrm{n}^{\circ}$ 11.700, de 13 de junho de 2008. Acrescenta inciso X ao caput do art. 4o da Lei no 9.394, de 20 de dezembro de 1996, para assegurar vaga na escola pública de Educação Infantil ou de ensino fundamental mais próxima de sua residência a toda criança a partir dos 4 (quatro) anos de idade. Diário Oficial [da] República Federativa do Brasil, Brasília, 16 jun. 2008a. Seção 1, p. 8.

. Lei no 11.738, de 16 de julho de 2008. Regulamenta a alínea "e" do inciso III do caput do art. 60 do Ato das Disposições Constitucionais Transitórias, para instituir o piso salarial profissional nacional para os profissionais do magistério público da educação básica. Diário Oficial [da] República Federativa do Brasil, Brasilia, 17 jul. 2008b. Seção 1, p. 1.

Lei $\mathrm{n}^{\circ}$ 11.494, de 20 de junho de 2007. Regulamenta o Fundo de Manutenção e Desenvolvimento da Educação Básica e de Valorização dos Profissionais da Educação (Fundeb). Diário Oficial [da] República Federativa do Brasil, Brasília, 21 jun. 2007. Seção 1, p. 7.

. Lei no 9.394, de 20 de dezembro de 1996. Estabelece as diretrizes e bases da educação nacional. Diário Oficial [da] República Federativa do Brasil, Seção 1, p. 27833-27841. Brasília, 23 dez. 1996b.

. Constituição [da] República Federativa do Brasil. Brasília: Senado Federal, 1988.

. Decreto-Lei no 2.848, de 7 de dezembro de 1940. Código Penal. Diário Oficial [da] República Federativa do Brasil. Seção 1, p. 2391, Brasília, 31 dez. 1940.

CAMPANHA NACIONAL PELO DIREITO À EDUCAÇÃO. Educação pública de qualidade: quanto custa esse direito? 2. ed. São Paulo: Campanha Nacional pelo Direito à Educação, 2011.

CARREIRA, Denise; PINTO, José Marcelino Rezende. Custo aluno-qualidade inicial: rumo à educação pública de qualidade no Brasil. São Paulo: Global, 2007. 128p. 
CNE. Parecer CNE/CEB n n $^{\circ}$, de 05 de maio de 2010. Brasília: Conselho Nacional de Educação, 2010b. Disponível em: <http://portal.mec.gov.br/ index.php?option $=$ com_docman\&task $=$ doc_download\&gid $=5368 \&$ Itemid $=>$. Acesso em: 18 abr. 2016.

DOURADO, Luiz Fernandes. Avaliação do Plano Nacional de Educação 2001-2009: questões estruturais e conjunturais de uma política. Educação \& Sociedade, Campinas, v. 31, n. 112, p. 677-705, jul./set. 2010.

IBGE. Projeção da população do Brasil por sexo e idade: 2000-2060. Disponível em: <http://www.ibge.gov.br/home/estatistica/populacao/ projecao_da_populacao/2013/default_tab.shtm>. Acesso em: 18 abr. 2016.

Pesquisa Nacional de Amostra de Domicílios (PNAD) - 2014. Disponível em: <http://www.ibge.gov.br/home/estatistica/populacao/ trabalhoerendimento/pnad2014/sintese_defaultxls.shtm>. Acesso em: 19 abr. 2016.

INEP. Censo escolar da educação básica - 2014. Disponível em: < http://portal. inep.gov.br/basica-censo-escolar-matricula>. Acesso em: 19 abr. 2016.

LIMA, Licínio C. A escola como organização educativa. 2. ed. São Paulo: Cortez, 2003. 189 p.

OBSERVATÓRIO do PNE. Disponível em: < http://www.observatoriodopne. org.br/metas-pne/1-educacao-infantil/indicadores>. Acesso em: 19 abr. 2016.

OLIVEIRA, Romualdo Portela. O direito à educação. In: OLIVEIRA, Romualdo Portela de; ADRIÃO, Theresa. (Org.). Gestão, financiamento e direito à educação. 3. ed. rev. São Paulo: Xamã, 2007. p. 15-41.

PEIXOTO, Edson Maciel; SCHUCHTER, Terezinha Maria; ARAÚJO, Vania Carvalho de. O "tempo integral" na Educação Infantil: financiamento, gestão e projeto político pedagógico em questão. In: ARAÚJO, Vania Carvalho de. (Org.). Educação Infantil em jornada de tempo integral: dilemas e concepções. Brasília, DF: Ministério da Educação; Vitória: Edufes, 2015. p. 125-160. 
PINTO, José Marcelino de Rezende; ALVES, Thiago. O Impacto Financeiro da Ampliação da Obrigatoriedade Escolar no Contexto do FUNDEB. Educação \& Realidade, Porto Alegre, v. 32, n. 2, p. 605-624, maio/ago. 2011.

EDSON MACIEL PEIXOTO é Doutor em Educação pela Universidade Federal do Espírito Santo. Professor e pesquisador do Instituto Federal do Espírito Santo - Campus Cachoeiro de Itapemirim. Professor do Mestrado em Educação Profissional e Tecnológica do Instituto Federal do Espírito Santo. e-mail: edsonpeixoto@ifes.edu.br

VANIA CARVALHO DE ARAÚJO é Doutora e pós-doutora em Educação. Professora Associado IV do Departamento de Educação, Política e Sociedade e do Programa de Pós-Graduação em Educação da UFES. Coordenadora do Grupo de Pesquisa "Infância, Educação, Sociedade e Cultura". e-mail: vcaraujoufes@gmail.com

Recebido em setembro de 2016

Aprovado em outubro de 2016 